\title{
INFLUÊNCIA DO MATERIAL DO DESTILADOR NA COMPOSIÇÃo QUÍMICA DAS AGUARDENTES DE CANA. PARTE II
}

Daniel R. Cardoso, Benedito S. Lima-Neto e Douglas W. Franco*

Departamento de Química e Física Molecular, Instituto de Química de São Carlos, Universidade de São Paulo, CP 780, 13560-970

São Carlos - SP

\section{Ronaldo F. do Nascimento}

Departamento de Química Analítica e Físico Química, Centro de Ciências, Universidade Federal do Ceará, CP 6035, 60455-900 Fortaleza - CE

Recebido em 11/12/01; aceito em 12/7/02

\begin{abstract}
INFLUENCE OF THE POT STILL MATERIAL ON THE CHEMICAL COMPOSITION OF BRAZILIAN SUGAR CANE SPIRIT. PART II. The quantitative chemical analysis of the Brazilian sugar cane spirit distilled from glass column packaged with copper, stainless steel, aluminum sponge, or porcelain balls is described. The main chemical compounds determined by gas chromatography coupled with flame ionization (FID) and flame photometric (FPD) detectors and liquid chromatography coupled with diode array detector are aldehydes, ketones, carboxylic acids, alcohols, esters and dimethylsulfite (DMS). The spirits produced either in columns filled with copper or aluminum pot still exhibits the lowest DMS contents but the higher sulfate and methanol contents, whereas spirits produced in stainless steel or porcelain showed higher DMS concentration and lower teors of sulfate ion and methanol. These observations are coherent with DMS oxidation to sulfate, with methanol as by product, in the presence of either copper or aluminum.
\end{abstract}

Keywords: Brazilian sugar cane spirits; pot still; chemical composition; spirits.

\section{INTRODUÇÃO}

Apesar de a produção brasileira de aguardente de cana estar estimada entre 1,5 a 2,0 bilhões de litros/ano, as exportações brasileiras representam apenas $0,5 \%$ do total produzido ${ }^{1}$. O Brasil exportou em 1995, 2,8 milhões de litros passando em 99 para 3,7 milhões de litros anuais. Estima-se um faturamento de US\$ 100 milhões com as exportações de aguardente em $2002^{1}$, ou seja espera-se exportar 50 milhões de litros. As perspectivas de crescimento devido ao processo de globalização do mercado são ressaltadas pelo Programa Brasileiro de Desenvolvimento de Aguardente da Cana, Caninha ou Cachaça (PBDAC) cujas atividades até o momento estão basicamente restritas a iniciativas ligadas à propaganda e "marketing". Paralelamente existe, por parte de segmento significativo dos produtores, em iniciativas isoladas, o interesse pelo melhoramento da qualidade dos seus produtos.

Faz-se, portanto, necessária ao lado de uma política de "marketing" agressiva, uma sensível melhoria na qualidade do produto, o que necessariamente impõe o estabelecimento de um controle de qualidade químico e sensorial bem superior ao existente.

O cobre, o material mais amplamente empregado na indústria de confecção de destiladores, sabidamente conduz à contaminação do destilado por íons cúprico ${ }^{2}$. A legislação brasileira limita o teor de cobre em bebidas destiladas em $5 \mathrm{mg} \mathrm{L}^{-13}$, entretanto a legislação de outros países não tolera mais que $2 \mathrm{mg} \mathrm{L}^{-1}$ de cobre nos destilados alcoólicos ${ }^{4}$. Embora nesta concentração o cobre não possa ser considerado como tóxico, a sua presença contribui para ressaltar o sabor ácido na bebida. Além disto, contrariamente aos polifenóis, substâncias consideradas protetoras por seu caráter redutor, os íons cobre (II) facilitam os processos oxidativos ${ }^{5,6}$. Em estudo recente observou-se uma tendência à correlação entre o teor de carbamato de etila

*e-mail: douglas@iqsc.sc.usp.br e o material do alambique, indicando a participação do cobre na formação de carbamato de etila ${ }^{7,8}$.

Na busca de soluções para controlar a contaminação do destilado por $\mathrm{Cu}^{2+}$, destiladores de colunas de aço inox, alumínio e porcelana têm sido utilizados na indústria de aguardente. Entretanto, observou-se que a ausência de cobre no destilador e/ou nas colunas conduz a um defeito organoléptico no produto, o qual apresenta aroma típico de sulfetos ${ }^{9,10}$.

Em trabalho anterior ${ }^{11}$ foi relatado o estudo quantitativo dos principais compostos orgânicos voláteis (aldeídos, acetona, ácidos carboxílicos, álcoois e ésteres) em amostras de aguardentes destiladas em destiladores de cobre e de aço inox.

Complementando aquele trabalho ${ }^{9}$, descreve-se neste artigo o estudo quantitativo de produtos destilados em colunas recheadas com alumínio ou porcelana. Também são apresentados resultados referentes aos teores de dimetilsulfeto, metanol e sulfato nestes destilados, e em destilados oriundos de colunas recheadas com cobre ou aço inox.

\section{PARTE EXPERIMENTAL}

\section{Equipamentos}

Os aldeídos e a acetona foram analisados na forma de suas respectivas 2,4-dinitrofenilidrazonas em um cromatógrafo líquido Shimadzu, modelo LC10AD, equipado com um injetor-Rheodyne, modelo 7125 ("loop" de $20 \mu \mathrm{L}$ ), e um detector espectrofotométrico UV-vis de arranjo de diodos Shimadzu, modelo SPD-M6A, utilizando uma coluna de fase reversa Shimadzu-C18 $(25 \mathrm{~cm}$ x $4.6 \mathrm{~mm} ; 5 \mu \mathrm{m})$. Os ácidos carboxílicos, álcoois superiores e ésteres foram determinados diretamente em um cromatógrafo a gás HP, modelo 5890A série II, equipado com um detector de ionização em chama (FID) e separados em uma coluna capilar de polietilenoglicol esterificado HP-FFAP (50 m x 
0,2 mm d.i; 0,33 $\mu \mathrm{m}$ ). Dimetilsulfeto (DMS) foi determinado em um cromatógrafo a gás, HP modelo 5890A, equipado com um detector fotométrico de chama (FPD) utilizando uma coluna capilar de polidimetilsiloxano HP-ULTRA1 (25 m x 0,2 mm d.i; 0,33 $\mu \mathrm{m})$. O teor de sulfato foi determinado, após reação com o sal cloroanilato de bário, em um espectrofotômetro Hitachi, modelo U3501.

\section{Reagentes}

Somente foram investigados os compostos majoritários anteriormente descritos na literatura de aguardente de cana ${ }^{11-15}$.

Os padrões de aldeídos, acetona, ácidos carboxílicos, álcoois, ésteres, sulfato de sódio e DMS foram sempre de grau analítico (Sigma, Aldrich). Os solventes:metanol, acetonitrila e o diclorometano foram de grau cromatográfico-HPLC (Mallinckrodt). A água utilizada foi previamente destilada e, a seguir, desionizada por um sistema Milli-Q (Millipore). O reagente 2,4-dinitrofenilidrazina (2,4-DNPH), obtido da Aldrich, foi purificado por três recristalizações sucessivas em metanol ${ }^{7}$. Os padrões das respectivas 2,4-dinitrofenilidrazonas dos aldeídos e da acetona foram preparados conforme descrito na literatu$\mathrm{ra}^{9-11}$ e confirmados por análise elementar efetuada no laboratório de análise elementar do Instituto de Química da USP. O cloroanilato de bário utilizado foi de pureza analítica (Carlo Erba).

\section{Preparo dos destilados}

Amostras de vinhos (caldos de cana fermentados), gentilmente fornecidas pelas Indústrias Müller de Bebidas (Pirasununga/SP), foram destiladas em colunas de vidro Pyrex de dimensões 1,50 m x $20 \mathrm{~mm}$ d.i, recheadas com esponjas de cobre, aço inox (316), alumínio ou esferas de porcelana. Frações de $500 \mathrm{~mL}$ de vinho foram destiladas em cada coluna, a uma temperatura de $97 \pm 3{ }^{\circ} \mathrm{C}$. As frações chamadas "coração ou corpo" foram coletadas à temperatura de $0{ }^{\circ} \mathrm{C}$ em banho de gelo e estocadas em frascos de vidro Pyrex, hermeticamente selados, em "freezer" $\left(-15^{\circ} \mathrm{C}\right)$ até a análise.

A repetibilidade do processo foi estimada (em cada caso) com base na análise de três amostras, oriundas de destilações independentes do mesmo vinho, no mesmo sistema. Cada amostra foi analisada em triplicata.

\section{Condições de análise}

A análise dos compostos carbonílicos foi efetuada utilizando-se metodologia previamente estabelecida ${ }^{9-11}$. Uma solução $0,4 \%$ de 2,4DNPH foi preparada dissolvendo-se $0,40 \mathrm{~g}(2 \mathrm{mmol})$ de 2,4dinitrofenilidrazina em 100,0 mL de acetonitrila. Em um frasco foram introduzidos, consecutivamente $1,00 \mathrm{~mL}$ da solução de 2,4DNPH, 4,00 mL da amostra e 50,0 $\mu \mathrm{L}$ de $\mathrm{HClO}_{4}$ 1,0 M. A solução resultante foi agitada e mantida à temperatura ambiente por $40 \mathrm{~min}$, alíquotas de 25,0 $\mu \mathrm{L}$ desta solução foram injetadas no cromatógrafo líquido. A separação foi efetuada usando metanol-água como fase móvel. O gradiente de eluição empregado foi metanol:água (65:35) por $6 \mathrm{~min}$, metanol:água (85:15) em $4 \mathrm{~min}$, metanol:água (80:20) em 10 min e metanol:água (65:35) em $5 \mathrm{~min}$. Fluxo de $1,00 \mathrm{~mL} \mathrm{~min}{ }^{-1}$. Os derivados foram quantificados empregando-se o método de padronização externa e a detecção ocorreu a $365 \mathrm{~nm}$.

Os ácidos carboxílicos, álcoois superiores e o acetato de etila foram analisados segundo metodologia previamente estabelecida ${ }^{12,13}$. O programa de temperatura utilizado foi $50{ }^{\circ} \mathrm{C}(4 \mathrm{~min})$ elevado para $190{ }^{\circ} \mathrm{C}$ (5 min) a $10{ }^{\circ} \mathrm{C} / \mathrm{min}$, a $230{ }^{\circ} \mathrm{C}$ (30 min) a $5{ }^{\circ} \mathrm{C} / \mathrm{min}$. A razão de "split" foi de 1:25. A vazão do gás de arraste na coluna foi de 1,3 $\mathrm{mL} \mathrm{min}^{-1}$ e para os gases de alimentação do detector foi de $30 \mathrm{~mL} \mathrm{~min}^{-1}$ de $\mathrm{H}_{2}$ e $300 \mathrm{~mL} \mathrm{~min}^{-1}$ de ar, respectivamente. Alíquotas de $1,00 \mu \mathrm{L}$ das amostras foram injetadas diretamente no cromatógrafo a gás. Os ácidos carboxílicos, álcoois superiores, ésteres foram quantificados empregando-se o método do padrão interno. O ácido nonanóico foi o padrão interno utilizado na quantificação dos ácidos carboxílicos e o hexanol foi o padrão interno usado na quantificação dos álcoois e ésteres. As concentrações dos padrões internos nas soluções-padrão e nas amostras foram de $250 \mathrm{mg} \mathrm{L}^{-1}$ para o ácido nonanóico e $700 \mathrm{mg} \mathrm{L}^{-1}$ para o hexanol. Os ácidos, álcoois e ésteres foram quantificados empregando-se o método da padronização interna.

DMS foi analisado usando-se metodologia previamente estabelecida ${ }^{9-10}$. O programa de temperatura utilizado foi $40{ }^{\circ} \mathrm{C}$ (4 min) elevado para $190{ }^{\circ} \mathrm{C}(1 \mathrm{~min})$ a $15{ }^{\circ} \mathrm{C} / \mathrm{min}$, então a $230{ }^{\circ} \mathrm{C}$ (2 min) a $20^{\circ} \mathrm{C} \min ^{-1}$. A razão de "split" foi de 1:5. A vazão do gás

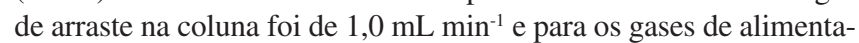
ção do detector foi de $80 \mathrm{~mL} \mathrm{~min}^{-1} \mathrm{de}_{2}$ e $100 \mathrm{~mL} \mathrm{~min}^{-1}$ de ar respectivamente. Alíquotas de 2,00 $\mu \mathrm{L}$ das amostras foram injetadas diretamente no cromatógrafo a gás. DMS foi quantificado empregando-se o método da padronização externa.

$\mathrm{O}$ teor de sulfato foi determinado diretamente nas amostras, via espectrofotométrica, utilizando como reagente o cloroanilato de bário $^{10,16}$. O método baseia-se na reação:

$$
\mathrm{SO}_{4}^{2-}+\mathrm{BaC}_{6} \mathrm{Cl}_{2} \mathrm{O}_{4} \text { (sólido) }+\mathrm{H}^{+} \rightarrow \mathrm{H} \mathrm{C}_{6} \mathrm{Cl}_{2} \mathrm{O}_{4}^{-}+\mathrm{Ba} \mathrm{SO}_{4} \text { (sólido) }
$$

O ácido cloranílico liberado estequiometricamente foi determinado por medidas de absorbância a 530nm. Embora a concentração dos cátions que possam interferir no procedimento de análise esteja abaixo de $10 \mathrm{mg} \mathrm{L}^{-1}$ na aguardente ${ }^{4}$, como medida de precaução as amostras foram percoladas por uma coluna $(\mathrm{L}=10 \mathrm{~cm} \times \mathrm{DI}=2 \mathrm{~cm})$ contendo uma resina DOWEX 50W-X8 (200-400 “mesh", forma $\mathrm{H}^{+}$.

\section{Análise quimiométrica}

PCA - "principal component analysis"17 - é uma manipulação matemática da matriz de dados originais, onde o objetivo é a representação da variância presente nas muitas variáveis usando um pequeno número de "fatores". A análise de PCA é baseada na correlação entre as variáveis. A PCA mapeia as amostras através de seus valores e as variáveis pelos respectivos pesos em um novo espaço definido pela componente principal. As componentes principais são simples combinações lineares das variáveis originais. O gráfico de valores ("scores") das amostras permite identificá-las, checando se são similares ou não, típicas ou atípicas. As variáveis mais importantes são identificadas pelos maiores pesos ("loadings"). Um ponto importante é que o máximo de variância em um conjunto de dados pode ser explicado por um reduzido número de variáveis. A componente principal é definida na direção de máxima variância no conjunto de dados e descreve o espalhamento máximo dos pontos de dados, e as variáveis subseqüentes são ortogonais, ou seja, não correlacionadas uma com a outra, e maximizam a variância restante. A extensão com que cada variável medida contribui para a PC (principal componente) depende de sua orientação relativa no espaço da PC e do eixo das variáveis. A contribuição de cada eixo para a PC é o cosseno do ângulo entre o eixo das variáveis e o eixo da PC, estes valores variam de -1 a 1 e são denominados de "loadings". Assim, uma vez removida a redundância, apenas os primeiros componentes principais são requeridos para descrever a maioria das informações contidas no conjunto de dados original.

Para uma melhor exploração dos dados obtidos para os diferentes compostos analisados nas amostras destiladas em colunas recheadas com diferentes materiais foi efetuado tratamento quimiométrico 
(análise multivariada) utilizando análise de componentes principais (PCA) com o auxílio do "software" SCILAB versão 2.6 (Scilab Group: INRIA-Rocquencourt Metalau Project).

O conjunto de dados original consistiu de 17 analitos (variáveis) e quatro amostras (média de triplicatas), gerando uma matriz de dados $[X=(3,17)]$ onde cada linha representa uma amostra e cada coluna, uma variável medida, o conjunto de dados original autoescalado antes da análise.

\section{RESULTADOS E DISCUSSÃO}

A Tabela 1 apresenta o teor dos principais aldeídos, ésteres, álcoois, ácidos carboxílicos, DMS e do íon sulfato nos produtos destilados em colunas recheadas respectivamente com cobre, aço inox, alumínio, ou porcelana. Os resultados obtidos nestes experimentos com as amostras destiladas em colunas recheadas com cobre ou com aço inox foram similares aos anteriormente relatados ${ }^{9}$.

O teor médio dos compostos carbonílicos nas amostras, à exceção do butiraldeído, variou acentuadamente em função do tipo de material da coluna (Tabela 1). O acetaldeído é o aldeído majoritário nestes destilados e o seu teor mais elevado foi verificado nas amostras destiladas em colunas recheadas com cobre $\left(19,0 \mathrm{mg} \mathrm{L}^{-1}\right)$. As concentrações de benzaldeído, valeraldeído e a acetona também variaram em função do material utilizado nas colunas de destilação obtendo-se os seguintes valores: cobre $\left(0,63 \mathrm{mg} \mathrm{L}^{-1}, 0,15 \mathrm{mg} \mathrm{L}^{-1}\right.$, $\left.0,41 \mathrm{mg} \mathrm{L}^{-1}\right)$, aço inox $\left(0,47 \mathrm{mg} \mathrm{L}^{-1}, 0,20 \mathrm{mg} \mathrm{L}^{-1}, 0,47 \mathrm{mg} \mathrm{L}^{-1}\right)$ e porcelana $\left(0,60 \mathrm{mg} \mathrm{L}^{-1}, 0,17 \mathrm{mg} \mathrm{L}^{-1}, 0,23 \mathrm{mg} \mathrm{L}^{-1}\right)$, respectivamente. As amostras destiladas em colunas recheadas com alumínio apresentaram os menores teores de compostos carbonílicos.

As concentrações dos ésteres (acetato de etila e caprilato de etila) também variaram significantemente em função do material de recheio da coluna de destilação. Os teores médios de acetato de etila e caprilato de etila foram maiores para as amostras destiladas em aço inox (108 $\mathrm{mg} \mathrm{L}^{-1}$ e $6,7 \mathrm{mg} \mathrm{L}^{-1}$ ) em relação aos demais destilados.

Semelhante comportamento foi observado para os teores de álcoois superiores, principalmente nas amostras destiladas na presença de aço inox $\left(78,2 ; 250 ; 1550 \mathrm{mg} \mathrm{L}^{-1}\right.$ para isopropanol, isobutanol e isoamílico, respectivamente). As amostras destiladas em colunas recheadas com alumínio apresentaram os menores teores de álcoois superiores $\left(33,5 ; 103 ; 655 \mathrm{mg} \mathrm{L}^{-1}\right.$ para isopropanol, isobutanol e isoamílico), e as amostras destiladas em colunas recheadas com cobre ou porcelana apresentaram um perfil intermediário.

Os maiores teores de metanol foram observados para as amostras destiladas em colunas recheada com alumínio $\left(5,28 \mathrm{mg} \mathrm{L}^{-1}\right) \mathrm{se}-$ guido das amostras destiladas em presença de cobre $\left(1,88 \mathrm{mg} \mathrm{L}^{-1}\right)$, aço inox $\left(1,15 \mathrm{mg} \mathrm{L}^{-1}\right)$ ou porcelana $\left(0,61 \mathrm{mg} \mathrm{L}^{-1}\right)$.

Não foram observadas variações significativas dos teores de ácidos carboxílicos, quer individualmente, quer em seu total, nas diversas amostras estudadas.

DMS é um composto secundário indesejável no aroma das aguardentes de cana, sendo responsável freqüientemente pelo aroma de repolho ${ }^{18}$. As amostras destiladas na presença de cobre e de alumínio apresentaram um teor médio de DMS (161 e $51 \mathrm{mg} \mathrm{L}^{-1}$ ) bem inferior às amostras produzidas em porcelana $\left(280 \mathrm{mg} \mathrm{L}^{-1}\right) \mathrm{e} \mathrm{em}$ aço inox (592 $\mathrm{mg} \mathrm{L}^{-1}$ ). Confirmou-se sensorialmente que as aguardentes de cana obtidas da destilação em colunas recheadas com aço inox ou porcelana apresentaram odor acentuado de sulfeto, contrariamente às amostras destiladas em colunas recheadas com alumínio ou cobre. É interessante mencionar que as amostras destiladas em alumínio ou cobre apresentam o melhor aroma. Porém, as amostras provenientes do destilador contendo alumínio conduziram a um produto não apropriado ao consumo, devido ao seu sabor ser considerado muito ruim pelos provadores.

Os resultados até agora obtidos reforçam os indícios anteriores ${ }^{9}$ de que a natureza dos materiais utilizados no enchimento das colunas não influencia no aspecto qualitativo de sua composição química, mas sim no quantitativo. São as seguintes as tendências dos dados quantitativos das funções estudadas em função do material: Teor de Aldeídos: cobre > aço inox > porcelana > alumínio; Teor de Álcoois superiores: porcelana $>$ aço inox $>$ cobre $>$ alumínio; Teor de Ácidos: variação insignificante; Teor de ésteres: aço inox $>$ cobre $>$ porcelana > alumínio; Teor de DMS: inox $>$ porcelana $>$ cobre $>$ alumínio; Teor de metanol: alumínio $>$ cobre $>$ inox $>$ porcelana; Teor de sulfato: alumínio $>$ cobre $>$ inox $>$ porcelana.

Tabela 1. Resultados médios ${ }^{\mathrm{a}}\left(\mathrm{mg} \mathrm{L}^{-1}\right)$ para os vários discriminadores químicos determinados nas aguardentes de cana destilada em colunas recheadas com diferentes materiais

\begin{tabular}{|c|c|c|c|c|}
\hline Analito & $\begin{array}{c}\text { Cobre }^{\mathrm{a}} \\
\text { (Desvio Padrão) }\end{array}$ & $\begin{array}{c}\text { Aço Inox }{ }^{\mathrm{a}} \\
\text { (Desvio Padrão) }\end{array}$ & $\begin{array}{c}\text { Alumínio }^{\mathrm{a}} \\
\text { (Desvio Padrão) }\end{array}$ & $\begin{array}{c}\text { Porcelana }^{\mathrm{a}} \\
\text { (Desvio Padrão) }\end{array}$ \\
\hline DMS & $161( \pm 1,50)$ & $592( \pm 10,4)$ & $51,0( \pm 1,20)$ & $280( \pm 2,30)$ \\
\hline Sulfato & $7,00( \pm 0,34)$ & $5,03( \pm 0,31)$ & $9,01( \pm 0,52)$ & $4,23( \pm 0,23)$ \\
\hline Metanol & $1,82( \pm 0,06)$ & $1,15( \pm 0,04)$ & $5,82( \pm 0,07)$ & $0,61( \pm 0,03)$ \\
\hline isoPropanol & $58,0( \pm 6,60)$ & $78,2( \pm 7,00)$ & $33,5( \pm 4,20)$ & $80,8( \pm 5,30)$ \\
\hline isoButanol & $203( \pm 6,90)$ & $250( \pm 6,40)$ & $103( \pm 3,20)$ & $257( \pm 7,01)$ \\
\hline isoAmílico & $1090( \pm 25,02)$ & $1550( \pm 37,04)$ & $655( \pm 17,02)$ & $1540( \pm 26,01)$ \\
\hline Ácido acético & $20,7( \pm 6,02)$ & $21,5( \pm 2,40)$ & $20,8( \pm 1,11)$ & $23,5( \pm 1,63)$ \\
\hline Ácido caprílico & $0,12( \pm 0,00)$ & $0,12( \pm 0,00)$ & $0,14( \pm 0,00)$ & $0,15( \pm 0,01)$ \\
\hline Ácido cáprico & $0,15( \pm 0,01)$ & $0,13( \pm 0,00)$ & $0,11( \pm 0,00)$ & $0,09( \pm 0,00)$ \\
\hline Ácido láurico & $0,02( \pm 0,00)$ & $0,01( \pm 0,00)$ & $0,01( \pm 0,00)$ & $0,03( \pm 0,00)$ \\
\hline Acetato de etila & $16,3( \pm 0,33)$ & $108( \pm 3,10)$ & $6,01( \pm 0,34)$ & $13,7( \pm 1,40)$ \\
\hline Caprilato de etila & $1,60( \pm 0,01)$ & $6,70( \pm 0,07)$ & $0,10( \pm 0,03)$ & $1,02( \pm 0,04)$ \\
\hline Acetaldeído & $19,0( \pm 0,43)$ & $9,01( \pm 0,21)$ & $5,54( \pm 0,28)$ & $5,85( \pm 0,53)$ \\
\hline Butiraldeído & $0,19( \pm 0,01)$ & $0,16( \pm 0,00)$ & $0,13( \pm 0,01)$ & $0,16( \pm 0,01)$ \\
\hline Valeraldeído & $0,15( \pm 0,00)$ & $0,20( \pm 0,00)$ & $0,08( \pm 0,00)$ & $0,17( \pm 0,00)$ \\
\hline Benzaldeído & $0,63( \pm 0,01)$ & $0,47( \pm 0,00)$ & $0,14( \pm 0,00)$ & $0,60( \pm 0,01)$ \\
\hline Acetona & $0,41( \pm 0,00)$ & $0,47( \pm 0,01)$ & $0,22( \pm 0,00)$ & $0,23( \pm 0,00)$ \\
\hline
\end{tabular}

${ }^{a}$ Média de 3 destilações distintas, injeções em triplicata 
Estes resultados também foram avaliados usando análise multivariada por meio de análise de componentes principais (PCA). O PC1 representa 53,62\% da variância no conjunto de dados iniciais e pode ser observado pelo gráfico de "loadings", Figura 2, que possui uma grande contribuição do DMS, metanol, sulfato, valeraldeído, benzaldeído e dos álcoois superiores (isobutanol, isoamílico e propanol). O PC2 representa $29,31 \%$ da variância do conjunto de dados iniciais e pode ser visualizada pelo gráfico de "loadings", Figura 2, uma maior contribuição dos ácidos capróico, láurico, acético, cáprico e da acetona. A variância acumulada no gráfico PC1 vs PC2 explica $82,3 \%$ da variância do conjunto de dados iniciais, Tabela 2.

Tabela 2. Dados de variância obtidos para cada componente principal

\begin{tabular}{ccc}
\hline $\begin{array}{c}\text { Componente } \\
\text { Principal }\end{array}$ & $\begin{array}{c}\text { Variância } \\
\text { Explicada }(\%)\end{array}$ & $\begin{array}{c}\text { Variância } \\
\text { Acumulada (\%) }\end{array}$ \\
\hline PC1 & 53,62 & 53,62 \\
PC2 & 29,31 & 82,93 \\
PC3 & 17,07 & 100 \\
PC4 & 0 & 0 \\
\hline
\end{tabular}

Observou-se que as amostras obtidas pela destilação em colunas recheadas com aço inox são os destilados cujos teores dos compostos estudados mais se assemelham aos destilados em colunas recheadas com cobre. As amostras destiladas em colunas recheadas com alumínio ou porcelana possuem características químicas e conseqüentemente sensoriais diferentes entre si e entre os destilados em aço inox e cobre, Figuras 1 e 2 . Estes resultados mais uma vez ressaltam a importância do uso do cobre na fabricação de destiladores.

As amostras destiladas em colunas de alumínio possuem em sua composição uma apreciável contribuição de íons sulfato e metanol, mas uma contribuição pouco significativa com relação ao teor de DMS.

As amostras destiladas em colunas recheadas com cobre ou alumínio apresentaram os maiores teores de sulfato e metanol e os menores teores de DMS, quando comparadas às amostras destiladas em aço inox ou porcelana (Tabela 1). Em painéis de degustação, os destilados em colunas recheadas com alumínio ou cobre apresentaram odor de "repolho"18 inferior aos obtidos da destilação em colunas recheadas com aço inox ou porcelana. Esta constatação é coerente com uma possível oxidação do DMS ${ }^{19}$.

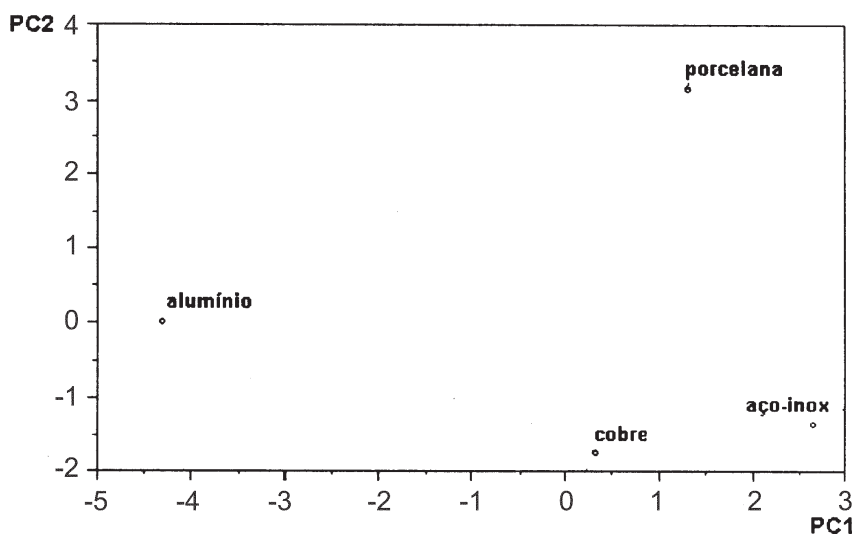

Figura 1. Gráfico de PCA scores para as aguardentes de cana destiladas em colunas de diferentes materiais. Amostras em triplicata

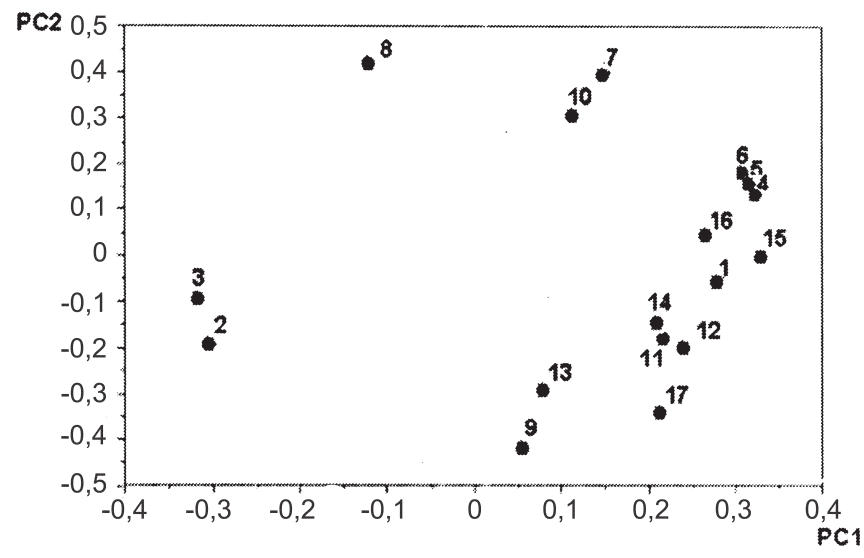

Figura 2. Gráfico de PCA loadings para os descriminadores químico determinados nas aguardentes de cana destiladas em colunas de diferentes materiais. Amostras em triplicata. $1=$ DMS; $2=$ Sulfato; $3=$ Metanol; $4=$ isopropanol; 5 = isobutanol; $6=$ isoamílico; 7 = Ácido acético; $8=$ Ácido caprílico; 9 = Ácido cáprico; 10 = Ácido láurico; 11 = Acetato de etila; 12 = Caprilato de etila; $13=$ Acetaldeído; $14=$ Butiraldeído; $15=$ Valeraldeído; $16=$ Benzaldeído; $17=$ Acetona

A maior diferença entre as amostras destiladas em cobre ou aço inox pode ser atribuída ao elevado teor de DMS encontrado nas amostras preparadas em colunas de aço inox, em conjunto aos elevados teores de ésteres encontrados nestas amostras. Novamente, é importante notar que as amostras com elevados teores de sulfato e metanol (colunas de alumínio ou cobre) possuem uma baixa contribuição de teores de DMS (Figuras 1 e 2). A recíproca é verdadeira, fortalecendo os indícios de que o alumínio e o cobre favorecem a oxidação do DMS.

A conversão de DMS em metanol e metil sulfeto em meio aquoso, por meio de radicais $\mathrm{OH} \cdot$ gerados por fotólise, foi recentemente relatado ${ }^{19}$. Gráficos de concentração de metanol versus concentração de sulfato mostram uma clara tendência a uma correlação linear. É também observada esta tendência em relação à razão das concentrações metanol/sulfato em função da concentração de DMS, sugerindo também uma coerência com a proposta acima. O esclarecimento da reação de conversão do DMS em íons sulfato, tendo o metanol como subproduto, está sendo objeto de uma investigação mais detalhada cujos resultados serão relatados futuramente.

\section{CONCLUSÕES}

Variando-se o material que compõe a coluna de destilação no processo de produção da aguardente de cana, alteram-se as características químicas e sensoriais do destilado, conforme os dados obtidos na publicação precedente e na atual. Dentre os materiais testados, o que mais se assemelha ao cobre é o aço inox, o qual apresenta a desvantagem de conduzir a teores elevados de DMS no destilado final. O esclarecimento do papel do cobre na oxidação de sulfeto em bebidas destiladas está presentemente em estudo.

\section{AGRADECIMENTOS}

Os autores agradecem à Indústria Müller de Bebidas Ltda. pelo fornecimento do caldo de cana fermentado, e à CAPES, CNPq e FAPESP pelo suporte financeiro. 


\section{REFERÊNCIAS}

1. Curso de aguardente de cana: Produto e Qualidade, de 27 a 29 de agosto de 2000, PBDAC: Jaboticabal, Brasil, p. 3.

2. Lima-Neto, B. S.; Bezerra, C. W.; Polastro, L. R.; Campos, P.; Nascimento, R. F.; Furuya, S. M. B.; Franco, D. W.; Quim. Nova 1994, 17, 220.

3. Ministério da Agricultura, Portaria $N^{\circ} 371$, Complemento de Padrões de Identidade e Qualidade para Destilados Alcoólicos, Brasília, DF, 18/04/ 1974.

4. Nascimento, R. F.; Bezerra, C. W.; Furuya, S. M. B.; Shultz, M. S.; Polastro, L. R.; Lima-Neto, B. S.; Franco, D.W.; J. Food Compos. Anal. 1999, 12, 17.

5. Morgens, L. A.; Skibsted, L. H.; J. Agric. Food Chem. 1998, 46, 1272.

6. Furuya, S. M.; Isique, W. D.; Lima-Neto, B. S.; Andersen, L. M.; Skibsted, L. H.; Franco, D. W.; Eur. Food Res. Technol., 2002, 215, 169.

7. Aresta, M.; Boscolo, M.; Franco, D.W.; J. Agric. Food Chem. 2001, 49, 2819

8. Andrade-Sobrinho, L. G.; Boscolo, M.; Lima-Neto, B. S.; Franco, D. W.; Quim. Nova, 2002, 25, 1074.
9. Nascimento, R. F.; Cardoso, D. R.; Faria, J. B.; Lima-Neto, B. S.; Franco, D. W.; Quim. Nova 1998, 21, 735.

10. Nascimento, R. F.; Tese de Doutorado, Universidade de São Paulo, Brasil, 1997.

11. Nascimento, R. F.; Marques, J. C., Lima-Neto, B. S.; De Keukeleire, D.; Franco, D. W.; J. Chromatogr., A 1997, 782, 13.

12. Nascimento, R. F.; Cardoso, D. R.; Lima-Neto, B. S.; Franco, D. W.; Chromatographia 1998, 48, 751.

13. Boscolo, M.; Bezerra, C. W.; Cardoso, D. R.; Lima-Neto, B. S.; Franco, D. W.; J. Braz. Chem. Soc. 2000, 11, 86.

14. Cardoso, D. R.; Furuya, S. M. B.; Lima-Neto, B. S.; Franco, D. W.; J. Food Compos. Anal., submetido.

15. Nascimento, R. F.; Cardoso, D. R.; Lima-Neto, B. S.; De Keukeleire, D. Franco, D. W.; J. Agric. Food Chem. 2000, 48, 6070.

16. Bertolacini, R. J.; Barney, J. E.; Anal. Chem. 1957, 29, 281.

17. Beebe, K. R.; Pell, R. J.; Seasholtz, M. B.; Chemometrics: a Practical Guide, Wiley: New York, 1998

18. Mestres, M.; Busto, O.; Guash, J.; J. Chromatogr., A 2000, 881, 569.

19. Barone, S. B.; Turnipseed, A. A.; Ravishankara, A. R.; J. Phys. Chem. 1996, 100,14694 